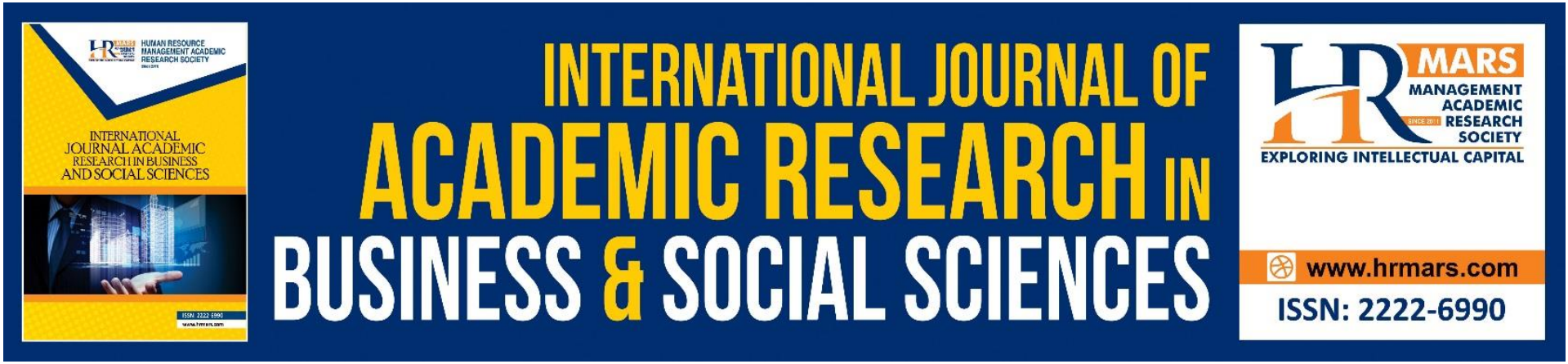

\title{
Delineating the Proof-Of-Concept of Virtual Reality for Interprofessional Education in Simulating Obesity Case Management
}

Barakatun Nisak M. Y., Norkamaliah H., Rafidah H., Puteri Shanaz J. K., and Zulfitri Azuan M. D.

To Link this Article: http://dx.doi.org/10.6007/IJARBSS/v11-i19/11741 DOI:10.6007/IJARBSS/v11-i19/11741

Received: 15 October 2021, Revised: 18 November 2021, Accepted: 30 November 2021

Published Online: 16 December 2021

In-Text Citation: (Nisak et al., 2021)

To Cite this Article: Nisak, B. M. Y., Norkamaliah, H., Rafidah, H., Shanaz, P. J. K., and Azuan, Z. M. D. (2021). Delineating the Proof-Of-Concept of Virtual Reality for Interprofessional Education in Simulating Obesity Case Management. International Journal of Academic Research in Business and Social Sciences, 11(19), 349-357.

\section{Copyright: @ 2021 The Author(s)}

Published by Human Resource Management Academic Research Society (www.hrmars.com)

This article is published under the Creative Commons Attribution (CC BY 4.0) license. Anyone may reproduce, distribute, translate and create derivative works of this article (for both commercial and non-commercial purposes), subject to full attribution to the original publication and authors. The full terms of this license may be seen at: http://creativecommons.org/licences/by/4.0/legalcode

Special Issue Title: Youth and Community Wellness, 2021, Pg. 349 - 357

Full Terms \& Conditions of access and use can be found at http://hrmars.com/index.php/pages/detail/publication-ethics 


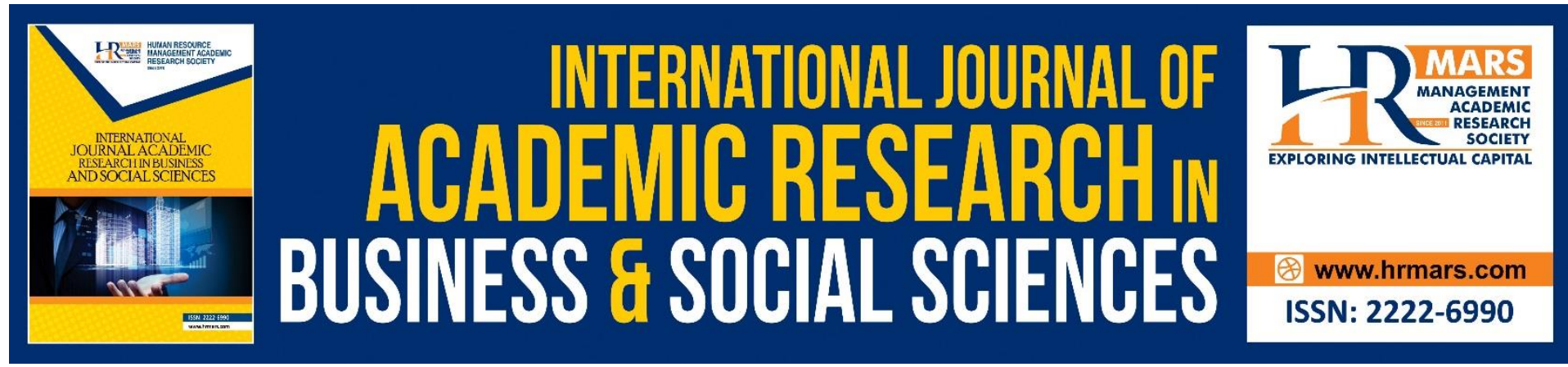

\title{
Delineating the Proof-Of-Concept of Virtual Reality for Interprofessional Education in Simulating Obesity Case Management
}

\author{
Barakatun Nisak M.Y ${ }^{1,2}$, Norkamaliah H. ${ }^{2}$, Rafidah H. ${ }^{3}$, Puteri \\ Shanaz J. K ${ }^{4}$, and Zulfitri Azuan M. D. ${ }^{2}$ \\ ${ }^{1}$ Institute for Social Science Studies, Universiti Putra Malaysia, 43400 UPM Serdang, \\ Selangor, Malaysia, ${ }^{2}$ Department of Dietetics, Faculty of Medicine and Health Sciences \\ Universiti Putra Malaysia, 43400 UPM Serdang, Selangor, Malaysia, ${ }^{3}$ Medical Education \\ Research \& Innovation Unit (MERIU), Department of Human Anatomy, Faculty of Medicine \\ and Health Sciences Universiti Putra Malaysia, ${ }^{4}$ Department of Family Medicine, Faculty of \\ Medicine and Health Sciences Universiti Putra Malaysia
}

Email: bnisak@upm.edu.my

\begin{abstract}
This article delineates the proof-of-concept of virtual reality for interprofessional education in simulating obesity case management among healthcare profession students. Healthcare profession students, including dietetics, medical and nursing students in Universiti Putra Malaysia, will be recruited as a sample. This study starts with a workshop session on IP simulation-based obesity education and will be integrated into the virtual world (VW) online software. Students' knowledge and attitude will be assessed pre and post of the virtual IPE exposures. The developed obesity-simulated case would successfully lead to IPE implementation, and students who received virtual IPE would significantly have a better knowledge of obesity management and a positive attitude towards IPE. The virtual IPE would be a practical pedagogical approach to prepare the health profession students for a collaborative environment, improve technical skills, and strengthen soft skills such as communicating effectively.
\end{abstract}

Keywords: Interprofessional Education, Interprofessional Collaboration, Healthcare Professionals, Virtual Reality, Obesity

\section{Introduction}

In a healthcare setting, working in a collaborative environment involving various professionals is a nascent strategy that helps boost professional standards in delivering the highest quality of patient care and produce significant health outcomes (Gilbert et al., 2010; Reeves et al., 2013). Nowadays, there is an increasing need to provide students with interprofessional education (IPE) in meeting the demand for practice in a multidisciplinary healthcare system. IPE means "learning together, from and with two or more professionals to facilitate effective teamwork and improve the health benefits and education" (Gilbert et al., 2010). 
IPE aims to educate clinical material in a relevant and interactive way (Levine \& Wren, 2013).

For the students, the advantages of IPE are evident. Students exposed to IPE in the syllabus has cultivated interprofessional collaborations during their practices, enhanced team spirit to overcome healthcare providers' limitations, and encouraged competencies (Al-Qahtani \& Guraya, 2016; Reeves et al., 2013; Cusack \& O'Donoghue, 2012). Implementation of IPE strengthened their attitudes towards collaborative management and inquisitiveness for patients care (Nango \& Tanaka, 2010).

Simulation-based education is a teaching strategy reflecting a real-world scenario for achieving educational objectives that have also been adopted when delivering IPE (Pai, 2018). Simulation in health education has been commonly used to mimic clinical procedures (Lateef, 2010). The World Health Organization (2013) supports the use of simulation-based education as a significant way to assist students to learn collaborative approaches as in IPE. This method provides students with appropriate circumstances for practising clinical theories and skills in a safe environment and supervised practice (Lamé \& Dixon, 2018). Furthermore, the idea of learning-by-doing using simulation-based education brings more attention and lasting memory than other forms of learning (WHO, 2013).

IPE is well-known for its practical benefits, which have been established in Australia, Canada, the United Kingdom, the United States, and Saudi Arabia (Fallatah, 2016; Khan et al., 2016; Sunguya et al., 2014). Still, there is insufficient data on IPE applications in developing countries, including South-East Asia (Sunguya et al., 2014). In Malaysia, research about IPE is currently still in its infancy. One of the reasons could be related to the nature of the healthcare programs, generally conducted in isolation, whereby teaching and learning methods are within the same professional (Tong et al., 2016). In other words, students are rarely meet those in other programs. However, they are expected to work as a team in practice. This is particularly relevant in our setting as the IPE has not been in the class arrangement, highlighting the need to initiate IPE in our current teaching and learning without interfering with the curriculum system.

We use obesity as a model of care as it is the most significant health issue globally. Within the Southeast Asian region, Malaysia has the highest prevalence of obesity (Mohamad Nor et al., 2018), where almost $40 \%$ of Malaysian adults are obese (Mohamad Nor et al., 2018). Obesity is a complex disease requiring multidisciplinary approaches in understanding patient issues. Although obesity has been regularly taught throughout medicine and allied healthcare syllabus, it is being communicated at the uni-professional level. It has been shown that using interprofessional collaboration practice in adults with obesity resulted in a significant weight loss (Nagelkerk et al., 2018). This article aims to delineate the proof-ofconcept of virtual reality for IPE in simulating obesity case management.

\section{Materials and Methods}

Study design and samples

This study is a pre-post intervention using a purposive sampling method and will be conducted at the Faculty of Medicine and Health Sciences, Universiti Putra Malaysia. This study will be carried out between October - December 2021. This study will be utilised a pre-post design, with a sample of healthcare profession students from different disciplines who are commonly engaged in obesity care such as dietetics, medical, and nursing program. The study was initiated with a workshop session on IPE education conducted in October 2019. The workshop's goal was to ensure students provided their input on the conduct of IPE and its 
perceived benefits. During the workshop, they are given a basic introduction about obesity and the critical needs of having the team approach to manage obesity. Then, the information gathered has been integrated into the web-based 3D virtual reality, in which the development process is explained subsequently.

\section{Sample Size}

A total of 50 students would be required in acquiring $20 \%$ improvement after following the online IPE learning about clinical leadership (Tschannen et al., 2018). The sample size has also considered a $10 \%$ drop out at the alpha level of 0.05 and $90 \%$ power.

\section{Development of Obesity Virtual Reality Clinic using Second Life ${ }^{\circledR}$ Platform}

This study developed virtual reality with the obesity clinic as a model using the Second Life ${ }^{\circledR}$ platform to provide an engaging and immersive learning experience that reflects students' real-clinical scenarios. The Second Life ${ }^{\circledR}$ is a platform that provides an immersive experience of a virtual world featuring 3D-based user-generated content that supports highly interactive networking. The platform has been used in health education, such as mental health, patient safety and emergency medicine (Baker, Wentz \& Woods, 2009; Davis, Hercelinskyj \& Jackson 2016). However, the use of Second Life for obesity management in implementing IPE is still scarce.

In this Second Life ${ }^{\circledR}$ platform, we created an obese individual who attended the obesity clinic that a group of healthcare professions students would manage (Figure 1). The patient would undergo the nutrition care process that includes assessment and intervention. The healthy concept of the cafeteria is built to support dietary changes that provide real-life experience for the students. The developed VR is ready to be tested for its feasibility. It would allow students from various locations to come together for a real-time interactive training to manage obesity collaboratively. The IPE using a simulation-based obesity education is a practical pedagogical approach to prepare the students for a collaborative environment, develop technical skills and enhance soft skills, such as communication and teamwork, to prepare them as work-ready graduates.

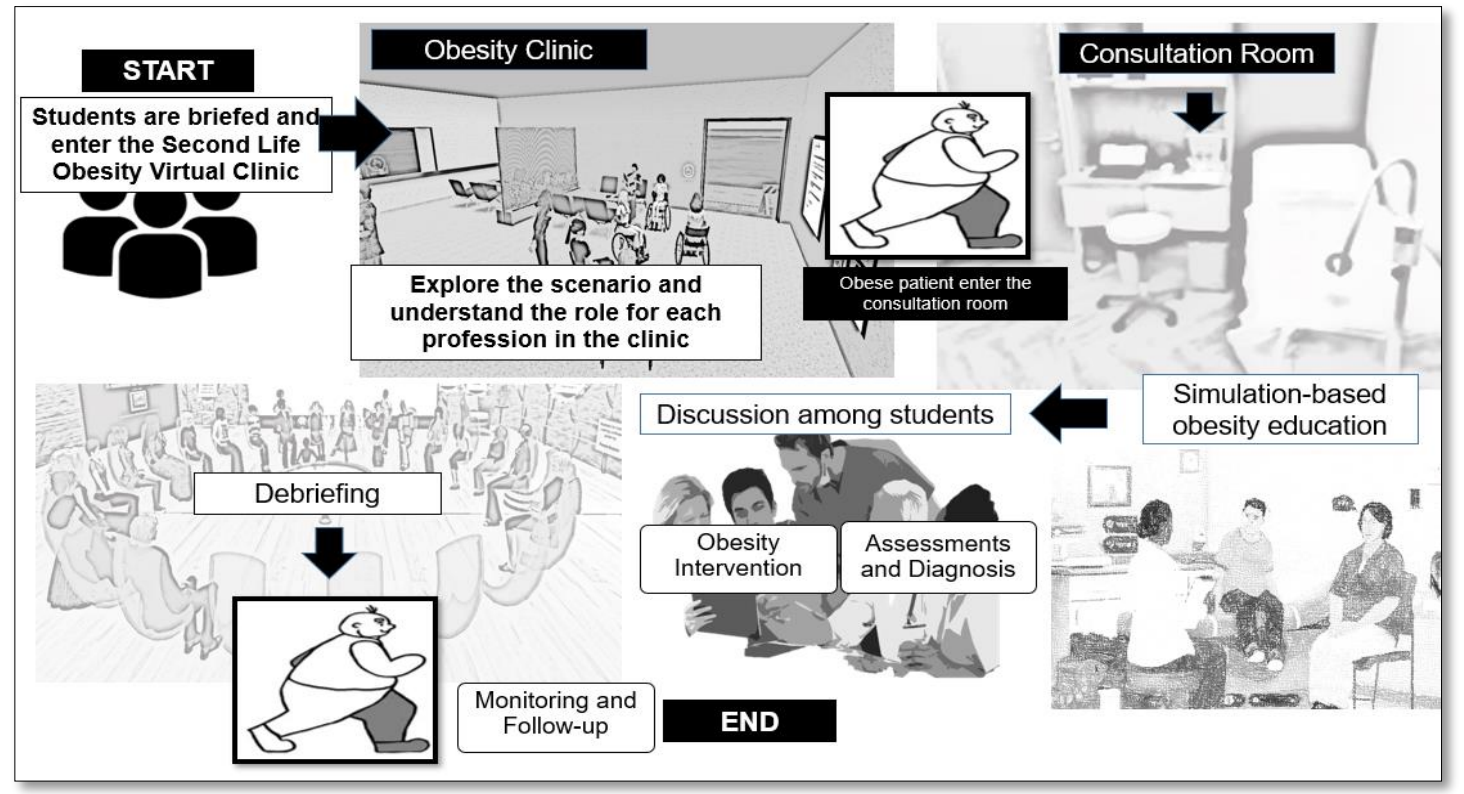

Figure 1: The map for Virtual Clinic for the interprofessional education using Second Life ${ }^{\circledR}$ Platform 


\section{Knowledge and Attitude}

The knowledge about obesity management will be assessed using a set of questionnaires that have been developed based on our obesity model-of-care module. Students are required to answer ten multiple-choice questions about managing obesity, which will be asked before and after the IPE. This module will be later integrated into the virtual reality platform to be used as a teaching tool of IPE simulation-based in obesity cases.

The knowledge and attitudes towards IPE behaviours will also be assessed using validated questionnaires, namely the Interprofessional Socialization and Valuing Scale (ISVS) (King et al., 2016). ISVS evaluate the knowledge, attitudes, and behaviour towards collaborative care approaches in a healthcare setting. A total of nine questions ask about the role of IPE in preparing healthcare profession students to take part in interprofessional healthcare teams. The ISVS was available in two formats (ISVS-9A and ISVS-9B), and both are used before and after the study, respectively. Items are rated on a 7-point scale ranging from "not at all" (1) "to a very great extent" (7).

\section{Values and Experiences}

The value and experiences related to IPE activities will be assessed using the predetermined Self-Reflection Analysis (SRA) format on their perspectives related to working as a team in managing obesity. There are six open-ended questions for the SRA section.

Students are also asked to provide feedback on the usability of the virtual reality platform. There are ten simple questions for this purpose. The questions are scored on a 5-point scale ranging from "strongly disagree" (1) to "strongly agree" (5). All questions are asked online via a Google survey form.

\section{Statistical Analysis}

All the data will be analysed using SPSS, and the level of statistical significance will be set at $p<0.05$. The demographic data and scores will be analysed and presented using means and standard deviations.

\section{Discussion}

This article delineates the proof-of-concept of virtual reality for IPE in the simulated obesity case management among healthcare profession students. Students from various health sciences programs, including dietetics, medical and nursing, will participate in the virtual reality simulation for obesity management. The improvement in knowledge of obesity and attitudes towards IPE will be assessed before and after the study.

Simulation-based education in IPE is not new. It has been used widely during rotations in hospitals, domiciliary care, community welfare programs, simulation-based program, workshops, and student-led lectures (Khan et al., 2016). Simulation-based education has also been imparted in IPE using standardised human models and mannequins (Lateef, 2010; Pai, 2018). In some studies, they have also combined the IPE at lab-based or using a real patientbased scenario (Lamé \& Dixon, 2018). Students performed tasks in a small interprofessional team using a simulated clinical setting and impersonated their roles (Bolesta \& Chmil, 2014).

The concept of interprofessional practice is essential among the healthcare team to ensure effective patient care. Hence, the proposed study will focus on developing the skills related to IPE among healthcare professional students. This study used obesity as a model as obesity is a complex disease requiring multidisciplinary team management (Baker et al., 2009; 
Bolesta \& Chmil, 2014; Pai, 2018). The use of IPE helps significantly improve their knowledge on obesity management and have a positive attitude towards IPE compared to before the exposure (Khan et al., 2016). Nonetheless, simulation-based IPE is less explored in our setting among our students. Although it can be applied in the current education system, we identified various challenges. These include time, space, and logistics (Table 1).

Table 1: Interprofessional Education Strategies and Its Reported Challenges

\begin{tabular}{lll}
\hline Interprofessional & Education & Reported Challenges \\
Strategies & & \\
\hline Simulated-patients & Costly & \\
& & \\
& & \\
Standardised-patients & training ${ }^{1}$ & \\
& - Busy clinics $^{2}$ \\
Case studies and seminar & - Patient safety $^{2}$ \\
& - Logistic concern $^{3}$ \\
& - Scheduling and coordinating various disciplines $^{4}$ \\
\hline
\end{tabular}

Besides, face-to-face IPE is always not feasible as the standard curriculum has been designed separately, whereby each medical, nursing, dietetic, and other health science program does not learn simultaneously and in the same class. Each program has its syllabus (Tong et al., 2016). Current practice manages patients at a single appointment under a single professional in the clinical setting, which may hinder the IPE approach. The patient follows the interventions to treat obesity and referrals to other health care providers when necessary. Hence, it does not support students to digest how to function as part of multidisciplinary teams.

The environment of crowded health centres limits the feasibility of actual patients to be used in IPE (Sunguya et al., 2014). As a result, students will have little thought about other professions and understand only their roles. The approach lacks patient-centred care, making patients find it difficult to clearly understand a healthcare provider's care plan (Khan et al., 2016), particularly in (Sunguya et al., 2014). Nonetheless, most studies used the conventional simulation method in the lab or clinical setting, with a limited study done in virtual reality. Therefore, using virtual reality technologies offers an excellent advantage for IPE simulationbased learning. There are many benefits to be gained with virtual IPE to help bridge the medical and healthcare education system gap. It provides ample incentives to support interprofessional collaboration.

This study delineates how the virtual reality platform can be used to complement the current education system with IPE, which offers a golden opportunity for our students. Using virtual reality-based simulation programs has been proved feasible (Davis A., 2015; Hu \& Lee, 2017). The benefits of virtual IPE have been reported (Hall et al., 2011; Patel et al., 2013; Wiecha et al., 2010), and potential use for health-related benefits has also been proven (Kamel et al., 2008; Gorini et al., 2008), with positive feedback (Lee \& Berge, 2011; Taylor et al., 2013; Davis et al., 2016). The teaching methods have been exciting and valuable for IPE implementation (Nagelkerk et al., 2018). Potential challenges related to virtual reality are also addressed, such as learning time, financial, sustainability issues, and technological concerns involved in using the platform. However, those problems can be dealt with by starting basic virtual reality activities (Baker et al., 2009).

Using IPE as illustrated in a virtual reality platform would foster and enhance their experiences (Baker et al., 2009; Bolesta \& Chmil, 2014; Pai, 2018). A collaborative approach 
in handling complex management, including obesity, would assist students to gain a better perspective towards holistic care approach and collaborative treatment (Khan et al., 2016). It is expected that students with prior IPE exposures would highly value the experiences and practice teamwork when they begin to work (Patel et al., 2013).

This study will benefit the healthcare professions students, where they will be able to learn the navigation, communication, and information-sharing skills of relevance to the online virtual environment and apply their discipline-specific patient assessment and care planning. Additionally, with the use of virtual reality in providing IPE simulation, students will be able to determine the overall process of the health journey of the obese patient. They can actively participate, discuss and develop a collaborative care plan from various treatment perspectives.

Students can experience virtual education depending on their ability to understand and repeat the assignment quickly. Also, students can readily meet each other in the virtual reality platform out of class time which can resolve the logistic issues such as scheduling in a real clinic time. Thereby, students can access information from all over the place and have sufficient time to revise their educational materials and practical experience (Hu \& Lee, 2017). Simulated patient use would have been demanding (i.e., costly) and not easy to replicate (Nestel et al., 2011). This virtual simulation gives students a digital learning experience that demonstrates real clinical situations in hospitals or clinics.

Students may explore virtual environments in which $\mathrm{n}$ the real world is not easily accessible (Davis A., 2015). In the case of obesity assessment, students must conduct a physical examination of the composition of body fatness. The students can accurately identify the body fatness site by having a virtual education. Most importantly, it provides safe training of newly acquired clinical skills and protects patient confidentiality (Bolesta \& Chmil, 2014). The students can also view and discuss a similar scenario using voice and text chat to identify the best care plan for the patients. This platform will help build up technical skills and strengthen students' soft skills (Davis et al., 2016).

\section{Conclusions}

Interprofessional collaborations are essential in healthcare practices, and thus, IPE is a crucial component to be added to the current curriculum. Although there are challenges in implementing the IPE in the existing healthcare curricula, there is a potential strategy to integrate IPE using pedagogical simulation approaches to the virtual reality platform environment that would help to close the gap in the current education system. Future studies should evaluate the developed virtual reality facility for other programs using different clinical case scenarios to enrich its usability and database.

\section{Acknowledgement}

This study is funded under the Teaching and Learning Initiative Research Grants of Universiti Putra Malaysia (Project No: 9323744)

\section{Author's Contribution}

Author 1: Barakatun-Nisak Mohd Yusof, Author 2: Norkamaliah Hashim, Author 3: Rafidah Hod, Author 4: Puteri Shanaz Jahn Kassim and Author 5: Zulfitri Azuan Mad Daud 


\section{References}

Al-Qahtani, M. F., Guraya, S. Y. (2016). Measuring the attitudes of healthcare faculty members towards interprofessional education in KSA. Journal of Taibah Univ Med Sci, 11:586e93.

Baker, S. C., Wentz, R. K., \& Woods, M. M. (2009). Using Virtual Worlds in Education: Second Life $^{\circledR}$ as an Educational Tool. The teaching of Psychology. 36(1), 59-64. https://doi.org/10.1080/00986280802529079.

Bolesta, S., \& Chmil, J. V. (2014). Interprofessional education among student health professionals using human patient simulation. American Journal of Pharmaceutical Education, 78(5), 94. https://doi.org/10.5688/ajpe78594.

Cusack, T., O'Donoghue, G. (2012). The introduction of an interprofessional education module: students' perceptions. Qual Prim Care. 20:231e8.

Davis, A. (2015). Virtual Reality Simulation: An Innovative Teaching Tool for Dietetics Experiential Education. The Open Nutrition Journal, 9, 65-75.

Davis, D. L., Hercelinskyj, G., \& Jackson, L. M. (2016). Promoting Interprofessional Collaboration: A Pilot Project Using Simulation. Journal of Research in Interprofessional Practice \& Education, 6(2), 1-15. https://doi.org/10.22230/jripe.2017v6n2a225.

Fallatah, H. I. (2016). Introducing inter-professional education in curricula of Saudi health science schools: An educational projection of Saudi Vision 2030. Journal of Taibah University Medical Sciences, Elsevier. https://doi.org/10.1016/j.jtumed.2016.10.008.

Gilbert, J. H. V., Yan, J., \& Hoffman, S. J. (2010). A WHO report: Framework for action on interprofessional education and collaborative practice. Journal of Allied Health, 39(SUPPL. 1), 196-197. https://doi.org/10.1111/j.1741-1130.2007.00144.x.

Gorini, A., Gaggioli, A., Vigna, C., \& Riva, G. (2008). A Second Life for eHealth: Prospects for the Use of 3-D Virtual Worlds in Clinical Psychology. Journal of medical Internet research, 10. e21. 10.2196/jmir.1029.

Hu, A. E., \& Lee, J. J. (2017). Virtual reality in education: a tool for learning in the experience age. International Journal of Innovation in Education, 4(4), 215. Retrieved from https://doi.org/10.1504/IJIIE.2017.10012691.

Kamel, B. M., \& Hetherington, L., \& Wheeler, S. (2008). Second Life: An Overview of the Potential of 3-D Virtual Worlds in Medical and Health Education. Health information and libraries journal, 24. 233-45. 10.1111/j.1471-1842.2007.00733.x.

Khan, N. S., Shahnaz, S. I., \& Gomathi, K. G. (2016). Currently available tools and teaching strategies for the interprofessional education of students in health professions: A literature review. Sultan Qaboos University Medical Journal, Sultan Qaboos University. Retrieved from https://doi.org/10.18295/squmj.2016.16.03.003.

Lamé, G., \& Dixon, W. M. (2018). Using clinical simulation to study how to improve quality and safety in healthcare. BMJ Simulation and Technology Enhanced Learning, bmjstel2018-000370. Retrieved from https://doi.org/10.1136/bmjstel-2018-000370.

Lateef, F. (2010). Simulation-based learning: Just like the real thing. Journal of Emergencies, Trauma, and Shock. 3(4), 348. Retrieved from https://doi.org/10.4103/0974-2700.70743.

Lee, A., \& Berge, Z. L. (2011). Second life in healthcare education: Virtual environment's potential to improve patient safety. Knowledge Management and E-Learning. 3(1), 1723.

Levine, D., \& Wren, M. (2013). Working Together: Interactive Interprofessional Learning in the Classroom. publication - MedEdPortal. https://doi.org/10.15766/mep_23748265.9329.

Mohamad Nor, N. S., Ambak, R., Mohd Zaki, N., Abdul Aziz, N. S., Cheong, S. M., Abd Razak, 
M. A., Aris, T. (2018). An update on obesity research pattern among adults in Malaysia: A scoping review. BMC Women's Health. 18(S1), 114. https://doi.org/10.1186/s12905-0180590-4.

Nagelkerk, J., Benkert, R., Pawl, B., Myers, A., Baer, L. J., Rayford, A., Jakstys, C. (2018). Test of an interprofessional collaborative practice model to improve obesity-related health outcomes in Michigan. Journal of Interprofessional Education and Practice, 11, 43-50. https://doi.org /10.1016/j.xjep.2018.02.001.

Nango, E. \& Tanaka, Y. (2010). Problem-based learning in a multidisciplinary group enhances clinical decision making by medical students: A randomised controlled trial. Journal of Medical and Dental Sciences, 57(1), 109-118. https://doi.org/10.11480/jmds.570112.

Pai, D. (2018). Use of simulation for undergraduate medical education. International Journal of Advanced Medical and Health Research, 5(1), 3. https://doi.org/10.4103/IJAMR.IJAMR_63_17.

Patel, V., \& Aggarwal, R., \& Cohen, D., \& Taylor, D., \& Darzi, A. (2013). Implementation of an Interactive Virtual-World Simulation for Structured Surgeon Assessment of Clinical Scenarios. Journal of the American College of Surgeons, 217. 270-9. 10.1016/j.jamcollsurg.2013.03.023.

Reeves, S., Perrier, L., Goldman, J., Freeth, D., \& Zwarenstein, M. (2013). Interprofessional education: Effects on professional practice (update). Cochrane Database of Systematic Reviews. 3, 1-277. Retrieved from https://doi.org/10.1002/14651858.CD002213.pub3.www.cochranelibrary.com.

Sunguya, B. F., Hinthong, W., Jimba, M., \& Yasuoka, J. (2014). Interprofessional education for whom? - Challenges and lessons learned from its implementation in developed countries and their application to developing countries: A systematic review. (J. R. Zunt, Ed.), PLoS ONE. https://doi.org/10.1371/journal.pone.0096724.

Taylor, M., Taylor, D., Kulendran, M., Gately, P., \& Darzi, A. (2013). Virtual worlds as a tool to facilitate weight management for young people. J Virtual Worlds Res, 6(1).

Tong, S. F., Mohamad, N., Tan, C. E., Efendie, B., Chelliah, K. K., \& Gilbert, J. H. (2016). The transition from uniprofessional towards interprofessional education: The Malaysian experience of a pragmatic model. In Leading Research and Evaluation in Interprofessional Education and Collaborative Practice. pp. 169-192. https://doi.org/10.1057/978-1-13753744-7_9.

Tschannen, D., Dorn, R., \& Tedesco, C. (2018). Improving knowledge and behavior of leadership and followership among the interprofessional team. Int J Med Educ, 9:182188. Published 2018 Jun 29. doi:10.5116/ijme.5b30.9a84

WHO. (2013). Transforming and scaling up health professionals' education and training. World Health Organization Guidelines. https://doi.org/10.1017/CBO9781107415324.004.

Wiecha, J., Heyden, R., Sternthal, E., \& Merialdi, M. (2010). Learning in a virtual world: experience with using second life for medical education. Journal of medical Internet research, 12(1). 